\title{
Role of Adding Diffusion-Weighted MR Imaging to Conventional MR Imaging in Evaluation of Ovarian Masses
}

\author{
OMNIA A. KAMAL, M.D.*; MONA A. ABDELWAHED, M.D.* and ESRAA O. FETOUH, M.Sc.** \\ The Department of Radiodiagnosis, Faculties of Medicine, Ain Shams* and Alexandria** Universities
}

\begin{abstract}
Background: Ovarian cancer is a leading cause of death among gynecological malignancies and the fifth most common cause of cancer deaths in women.

Aim of Study: To determine whether the addition of DW sequences to a conventional MR imaging protocol can help in the prediction of the nature of suspicious ovarian masses which are detected previously by conventional ultrasound.

Patients and Methods: Thirty-five female patients with initial undetermined ovarian lesions were included in this study during the period from December 2019 to September 2020. Women who present with an ovarian mass on previous US examination and were referred to the Radiology Department of Alexandria Main University Hospital and Radiology Department of Ain Shams University Hospitals for further assessment and characterization by MRI imaging with adding DW-MR imaging Sequence.

Results: In the current study, the mean patient age was $41.00 \pm 13.37$ years. $17(48.57 \%)$ of 35 ovarian masses were benign, and $12(34.29 \%)$ were malignant, and $6(17.14 \%)$ were borderline. Diffusion-weighted MRI findings of the different histopathological types showed restricted diffusion in $83.3 \%$ of borderline lesions and $91.7 \%$ of malignant lesions while only $17.6 \%$ of benign lesions showed restriction diffusion with a statistically significant difference at $p$-value $0.025^{*}$. DWI had shown $91.7 \%$ sensitivity and low specificity $82.4 \%$. Combined DWI and conventional MRI sequences had the highest accuracy $93.1 \%$, and sensitivity at $95.3 \%$.
\end{abstract}

Conclusion: Our results concluded that the DWI can help and increase the confidence of MRI in assessment or exclude potential malignancy in ovarian masses.

Key Words: Ovarian mass - MRI - Diffusion-weighted $A D C$.

\section{Introduction}

OVARIAN cancer is a leading cause of death among gynecological malignancies and the fifth most common cause of cancer deaths in women. Because most patients with ovarian cancer present in an advanced stage of the disease due to its silent

Correspondence to: Dr. Esraa O. Fetouh,

E-Mail: esraahazem9317@gmail.com clinical course, a non-invasive and accurate diagnostic tool would be highly desirable [1]

Ovarian masses represent a special diagnostic challenge when imaging findings cannot be categorized into benign or malignant pathology [2] Excessive surgical procedures such as bilateral oophorectomy with or without hysterectomy have sometimes been performed in patients with benign ovarian tumor because the preoperative diagnosis was inaccurate [3] so a preoperative diagnosis of ovarian tumors based on imaging is important as the biopsy is not commonly applied [4]

Ultrasound (US) is the first-line imaging investigation for suspected adnexal masses helping in the detection and characterization of ovarian tumors [2] . Computed tomography (CT) is commonly performed for evaluation of suspected ovarian malignancy, but it exposes patients to radiation. Magnetic resonance image (MRI) can be a valuable problemsolving tool, an adjunctive modality for evaluating adnexal lesions, useful to give also surgical planning information without radiation exposure $[\mathbf{5 , 6}]$

MRI is able to identify different types of tissue contained in pelvic masses, distinguishing benign from malignant ovarian tumors, with an overall accuracy of $88 \%$ to $93 \%$ [2]. MRI can specifically diagnose certain pathologic types by providing accurate information on fat, collagen, and haemorrhage [7]. However, the only definitive diagnosis of an ovarian mass is through histology [8] .

Diffusion-weighted imaging is a functional MRI technique that measures the random microscopic water molecules movement (Brownian motion) [9] . Any pathological processes that affect intracellular and extracellular water mico-diffusivity will be reflected in DWI [10]. Diseases altering cell membranes, tissue cellularity, the viscosity of intracellular or extracellular water, and extracellular 
space tortuosity will cause changes in DWI [11] High signal on DWI reflects restricted diffusion [12].

Typically, DW-MRI permits a quantitative evaluation by assessing apparent diffusion coefficient (ADC) values which measure the random motion rate of water molecules and decreases with increased tumor cellularity [13]. In general, malignant tumors have higher cellularity than benign tumors; therefore, DWI can assist in differentiating malignant from benign tumors [14]

The purpose of this study is to determine whether the addition of DW sequences to a conventional MR imaging protocol can help in the prediction of the nature of suspicious ovarian masses which are detected previously by conventional ultrasound.

\section{Patients and Methods}

\section{Patients:}

Thirty-five females patients with initial undetermined ovarian lesions were included in this study; their ages ranged between 19-65 years with a mean value of $41 \pm 13.37$ years. The patients were referred from gynecology outpatient clinics to the Radiology Department of Alexandria Main University Hospital and Radiology Department of Ain Shams University Hospitals for MRI examination during the period from December 2019 to September 2020 .

\section{Inclusion criteria:}

Women who present with an ovarian mass on previous US examination and were referred for further assessment and characterization by MRI imaging with adding DW-MR imaging Sequence.

\section{Exclusion criteria:}

- Patients with any contraindication to MRI e.g. prosthetic heart valves.

- Patients with any contraindication to contrast media administration e.g. patients with GFR below $30 \mathrm{~mL} / \mathrm{min} / 1.73 \mathrm{~m}^{2}$.

Ethical considerations: Official permissions were obtained from the Radiology Department, Faculty of Medicine, Ain Shams University. Each included patient was informed about the nature of the study and written consent was obtained. The privacy of participants and confidentiality of data were guaranteed during the various phases of the study.

\section{Methods:}

All participated women in the study were subjected to full history taking, revision of the patient's laboratory investigations as tumor markers, MRI examination, and the final diagnosis was reached by surgical (laparoscopic) findings and histopathological examination.

MRI examination was performed by using a 1.5 T machine (Achieva Philips medical system) using eight-channel surface coil. The examination time was 35-50 minutes. Slice thickness ranged from $3-5 \mathrm{~mm}$ with a $1 \mathrm{~mm}$ gap.

\section{MRI Study protocol:}

- Axial T1WI (TR/TE, 500/10ms) and axial T2WI (TR/TE, 3300/100ms), slice thickness (6mm), Gap (1mm), FOV (32-42 cm), Matrix (256x256).

- Sagittal T2WI and Coronal T2WI, Slice thickness $(8-10 \mathrm{~mm})$, Gap $(1 \mathrm{~mm})$, FOV $(40-50 \mathrm{~cm})$, Matrix (256x256).

- Axial T1-weighted fat suppressed gradient-echo (GRE) sequence (TR/TE $(180 / 2,1)$, flip angle $\left(80^{\circ}\right)$, section thickness $(6 \mathrm{~mm})$, interslice gap $0.6 \mathrm{~mm}$; bandwidth $(62.5) \mathrm{kHz}$; field of view $(38 \mathrm{~cm})$, matrix $(256 \times 224)$.

- Post enhancement T 1 WI (axial and coronal) with fat suppression after injection of $0.1 \mathrm{mmol} / \mathrm{kg}$ of body weight of Gd-DTPA.

- DW-MRI in the axial plane by using a singleshot echo-planar imaging sequence with $b$ values $(0,300,600)$, TR/TE $(5000 / 70)$, Slice thickness $(6 \mathrm{~mm})$, Gap $(1 \mathrm{~mm})$, FOV $(36 \mathrm{~cm})$, Matrix (128x128).

\section{Study interpretation:}

Images were analyzed and signal intensity (SI) assessment was performed on picture archiving and communication system (PACS) workstation. The morphological features of each lesion were recorded. Malignant MR criteria were applied according to Valentini et al.'s criteria [2] of malignancy. Signal intensity on diffusion images with measurement of ADC values was assessed. All imaging findings of DW-MRI were correlated to the final diagnosis of histopathological examination.

\section{Statistical analysis:}

Recorded data were analyzed using the statistical package for social sciences, version 20.0 (SPSS Inc., Chicago, Illinois, USA). Quantitative data were expressed as mean \pm standard deviation (SD). Qualitative data were expressed as frequency and percentage. The following tests were done: ANOVA test when comparing between more than two means. Chi-square $\left(\mathrm{x}^{2}\right)$ test of significance was used to compare proportions between qualitative parameters. Receiver operating characteristic 
(ROC curve) analysis was used to find out the overall predictivity of parameters and to find out the best cut-off value with detection of sensitivity and specificity at this cut-off value.

The confidence interval was set to $95 \%$ and the margin of error accepted was set to $5 \%$. So, the $p$ value was considered significant when $\leq 0.05$, highly significant when $\leq 0.001$, and insignificant when $>0.5$.

\section{Results}

Table (1) shows the mean age of the studied group was $41 \pm 13.37$ years. The histopathological classification shows nearly half of the cases were benign $(48.57 \%)$. The most common clinical presentation was pelvic pain in $29(82.86 \%)$.

Table (2) shows the right side lesions $(77.14 \%)$ are more frequent than the left side lesions $(22.86 \%)$. The mean mass size is $20.5 \pm 25.6$. The unilateral lesions $(62.86 \%)$ are more common than bilateral lesions (37.14\%). The commonest mass descriptions were unilocular cyst, multilocular cysts, and complex cystic and solid, representing $37.14 \%, 31.43 \%$, and $28.57 \%$, respectively.

MRI T1WI showed Hypointense ovarian masses in $16(45.71 \%)$ patients (Figs. 1,2), Hyperintense ovarian masses found in 11( $31.43 \%)$ patients Intermediate signal ovarian masses found in 4 (11.43\%) patients (Fig. 3), Heterogenous hyperintense ovarian masses found in $3(8.57 \%)$ patients Heterogeneous hypo intense ovarian masses in 1 (2.86\%) patients. MRIT2WI showed Hyperintense ovarian mass: in 22(62.86\%) patients (Figs. 1,3). Heterogeneous hyperintense ovarian masses in 11 (31.43\%) patients (Fig. 2). Hypointense ovarian mass: in $2(5.71 \%)$ patients. MRI T 1 fat suppression showed fat suppression in $5(14.29 \%)$ patients and no suppression in $30(85.71 \%)$ patients. Postcontrast MRI showed enhancing wall in 18 $(51.43 \%)$ patients, enhancing septation in 17 $(48.57 \%)$ patients, enhancing mass found in 10 (28.57\%) patients, and enhancing nodule in 10 (28.57\%) patients (Table 3 ).

Table (4) demonstrates the MRI DWI findings. There are Restricted diffusion in 19 (54.29\%) patients (Fig. 1) and no Restricted Diffusion in 16 (45.71\%) patients (Figs. 2,3). ADC value of the Solid Component was ranged between 0.6-1.5 with

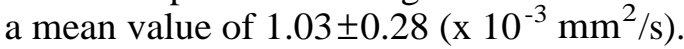

Laparoscopic study of ovarian masses revealed extra findings illustrated in Table (10). The most common extra finding was the ascitic fluid positive for malignant cells in 3 patients $(8.57 \%$ ) (Table $5)$.

The histopathological diagnosis of benign, borderline, and malignant lesions are described in Table (6). The most common benign lesions are endometriotic cyst (14.29\%) and mature cystic teratoma (14.29\%) (Fig. 2). The most common borderline lesions are mucinous tumor $(5.71 \%)$ and Papillary serous tumor $(5.71 \%)$. While the most common malignant lesions are Krukemburg tumor $(5.71 \%)$, Mucinous cystadenocarcinoma $(5.71 \%)$, and Papillary serous cystadenocarcinoma (5.71\%) (Fig. 1). (Table 6s).

Comparing different histopathological types group according to patient's conventional MRI (T1 fat sat.) study showed no fat suppression in $100 \%$ of both malignant and borderline types while $70 \%$ in the benign group with a statistically significant difference at $p$-value $0.046^{*}$. While comparing different histopathological types according to the patient's conventional MRI (Contrast Study) showed that the presence of enhancing (mass, septation, wall and nodule) was more common with malignant and borderline masses. At the same time, it was $0 \%$ in benign masses with a statistically significant difference at $p$-value $0.001 *, 0.012 *$, $0.001 *, 0.001 *$ respectively. DW MRI findings of the different histopathological types showed restricted diffusion in $83.3 \%$ of borderline lesions and $91.7 \%$ of malignant lesions while only $17.6 \%$ of benign lesions showed restriction diffusion with a statistically significant difference at $p$-value $0.025^{*}$. (Table 7).

Comparing different histopathological types according to the ADC value of the solid component of the lesions showed that there were statistically significant differences at $p$-value $0.038^{*}$, while the ADC value of the cystic component of the lesions showed that there were no statistically significant differences at $p$-value 0.267 . (Table 8 ).

Table (9) demonstrates ROC curve analysis to predict the accuracy of conventional MRI by T1 Fat Sat. in the characterization of ovarian masses in comparison to histopathology. The accuracy in predicting borderline and benign were $47.8 \%$ with sensitivity and specificity of $100 \%$ and $29.4 \%$ respectively. While the accuracy to predict borderline and malignant were $100 \%$ with $100 \%$ sensitivity. The accuracy to predict malignant and benign were $58.6 \%$ with sensitivity and specificity of $100 \%$ and $29.4 \%$ respectively. 
Table (1): Demographic data, histopathology, and clinical presentation of the studied population.

\begin{tabular}{ll}
\hline Demographic data & Total $(\mathrm{n}=35)$ \\
\hline Age (years): & \\
Mean \pm SD & $41 \pm 13.37$ \\
Histopathological classification: & Total $(\mathrm{n}=35)$ \\
Benign & $17(48.57 \%)$ \\
Borderline & $6(17.14 \%)$ \\
Malignant & $12(34.29 \%)$ \\
Clinical presentation: & Total $(\mathrm{n}=35)$ \\
Abdominal Pain & $3(8.57 \%)$ \\
Abdominal Swelling & $2(5.71 \%)$ \\
Pelvic Pain & $29(82.86 \%)$ \\
Vaginal Bleeding & $1(2.86 \%)$ \\
\hline
\end{tabular}

Table (2): Descriptive statistical data of mass site, size, laterality, and morphology by MRI.

\begin{tabular}{ll}
\hline Mass & Total $(\mathrm{n}=35)$ \\
\hline Site: & \\
$\quad$ Left & $8(22.86 \%)$ \\
$\quad$ Right & $27(77.14 \%)$ \\
Mass size: & \\
$\quad$ Mean \pm SD & $20.50 \pm 25.60$ \\
Laterality: & \\
$\quad$ Unilateral & $22(62.86 \%)$ \\
$\quad$ Bilateral & $13(37.14 \%)$ \\
Mass description: & Total $(\mathrm{n}=35)$ \\
$\quad$ Unilocular cyst & $13(37.14 \%)$ \\
$\quad$ Multilocular cyst & $11(31.43 \%)$ \\
$\quad$ Complex cystic and Solid & $10(28.57 \%)$ \\
Papillary projection & $6(17.14 \%)$ \\
$\quad$ Solid & $2(5.71 \%)$ \\
\hline
\end{tabular}

Table (3): Descriptive statistical data of MRI T1, T2 signal intensity, T1 fat sat, and contrast study of the ovarian masses in the study population.

\begin{tabular}{ll}
\hline MRI signal & Total $(\mathrm{n}=35)$ \\
\hline MRI signal Tl WI: & \\
Hyperintense & $11(31.43 \%)$ \\
Hypointense & $16(45.71 \%)$ \\
Heterogeneous hypointense & $1(2.86 \%)$ \\
Heterogenous hyperintense & $3(8.57 \%)$ \\
Intermediate signal & $4(11.43 \%)$ \\
MRI signal T2 WI: & \\
Hypointense & $2(5.71 \%)$ \\
Hyperintense & $22(62.86 \%)$ \\
Heterogeneous hyperintense & $11(31.43 \%)$ \\
Conventional MRI: & \\
T1 Fat Sat.: & \\
No Suppression & \\
Suppression & $30(85.71 \%)$ \\
Contrast Study: & $5(14.29 \%)$ \\
Enhancing Mass & \\
Enhancing Septation & $10(28.57 \%)$ \\
Enhancing Wall & $17(48.57 \%)$ \\
Enhancing Nodule & $18(51.43 \%)$ \\
\hline
\end{tabular}

Table (4): Descriptive data of DWI and ADC value (x10 ${ }^{-3}$ $\mathrm{mm}^{2} / \mathrm{s}$ ) of the Solid Component.

\begin{tabular}{ll}
\hline Diffusion-weighted MR imaging & Total $(\mathrm{n}=35)$ \\
\hline Restricted Diffusion & $19(54.29 \%)$ \\
No Restricted Diffusion & $16(45.71 \%)$ \\
$\begin{array}{l}\text { ADC value of the Solid Component } \\
\left(x 10^{-3} \mathrm{~mm}^{2} / \mathrm{s}\right):\end{array}$ & Total $(\mathrm{n}=35)$ \\
$\quad$ Mean $\pm \mathrm{SD}$ & $1.03 \pm 0.28$ \\
\hline
\end{tabular}

Data are presented as mean \pm SD or number $(\%)$.

Table (5): Descriptive statistical data of different radiological findings in the studied population.

\begin{tabular}{lc}
\hline Laparoscopic findings & Total $(\mathrm{n}=35)$ \\
\hline Ascitic fluid positive for malignant cells & $3(8.57 \%)$ \\
$\begin{array}{l}\text { Positive carcinoma cells in the peritoneal } \\
\text { wash fluid, papillary errosive cervicitis }\end{array}$ & $1(2.86 \%)$ \\
$\begin{array}{l}\text { Proliferative endometrial polyp, Interstitial } \\
\text { leiomyoma, Endometriosis }\end{array}$ & $1(2.86 \%)$ \\
Metastic nodule on the omentum and posterior & $1(2.86 \%)$ \\
$\quad$ wall of the uterus & $1(2.86 \%)$ \\
$\begin{array}{l}\text { Ovary, Both tubes omentum are positive for } \\
\text { tumor tissue }\end{array}$ & $1(2.86 \%)$ \\
$\begin{array}{l}\text { Ovarian follicular cysts } \\
\text { Endocervicitis, nabothian cysts }\end{array}$ & $1(2.86 \%)$ \\
\hline
\end{tabular}

Table (6): Descriptive statistical data for histopathological findings.

\begin{tabular}{ll}
\hline Histopathological diagnosis & $(\mathrm{n}=35)$ \\
\hline Benign: & \\
Emdometritic cyst & $5(14.29 \%)$ \\
Inclusion cyst & $1(2.86 \%)$ \\
Infarcted simple serous cyst surrounded by & $1(2.86 \%)$ \\
$\quad$ infarcted tubo ovarian tissue & \\
Mucinous cyst adenoma & $2(5.71 \%)$ \\
Pelvic inflammatory process (PID) tubo & $2(5.71 \%)$ \\
$\quad$ ovarian abscess & $1(2.86 \%)$ \\
Serous cyst adenoma complicated by & \\
$\quad$ ovarian torsion & $5(14.29 \%)$ \\
Mature cystic teratoma & \\
Borderline: & $2(5.71 \%)$ \\
Mucinous tumor & $1(2.86 \%)$ \\
Borderline mucinous cystadenocarcinom & $1(2.86 \%)$ \\
Borderline serous cystadenocarinoma & $2(5.71 \%)$ \\
Papillary serous tumor & \\
Malignant: & $2(5.71 \%)$ \\
Krukemburg tumor & $1(2.86 \%)$ \\
Moderately differentiated mucinous & \\
$\quad$ carcinoma grade 2(G2) & $1(2.86 \%)$ \\
Mucinous carcinoma high grade & $2(5.71 \%)$ \\
Mucinous cyst adenocarcinoma & $1(2.86 \%)$ \\
Papillary serous carcinoma, high grade with & \\
rupture capsule & $2(5.71 \%)$ \\
Papillary serous cystadenocarcinoma & $1(2.86 \%)$ \\
Sex cord tumor & $1(2.86 \%)$ \\
Undifferentiated ovarian carcinoma & $1(2.86 \%)$ \\
Serous cyst adenocarcinoma high grade & \\
\hline Data areprente & \\
\hline
\end{tabular}

Data are presented as mean \pm SD or number $(\%)$. 




(A)

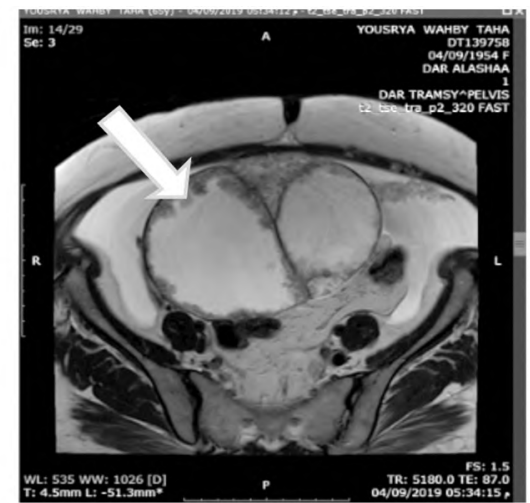

(B)

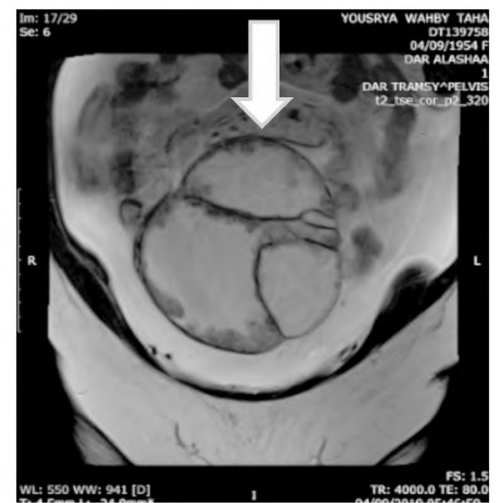

(C)

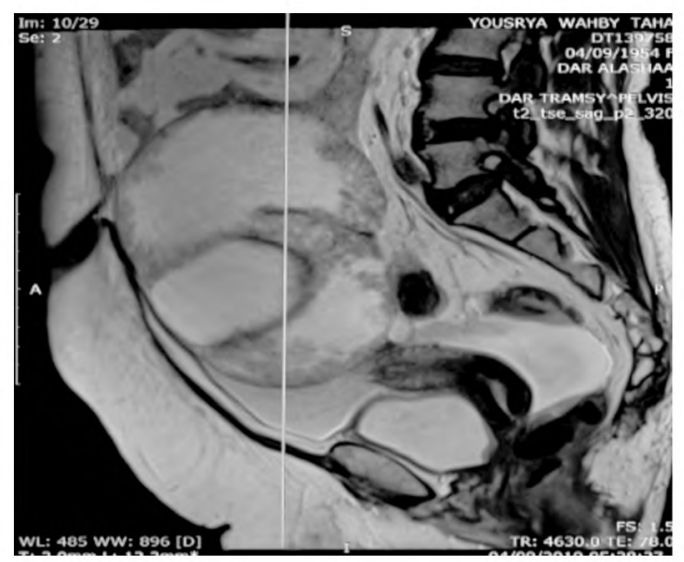

(D)

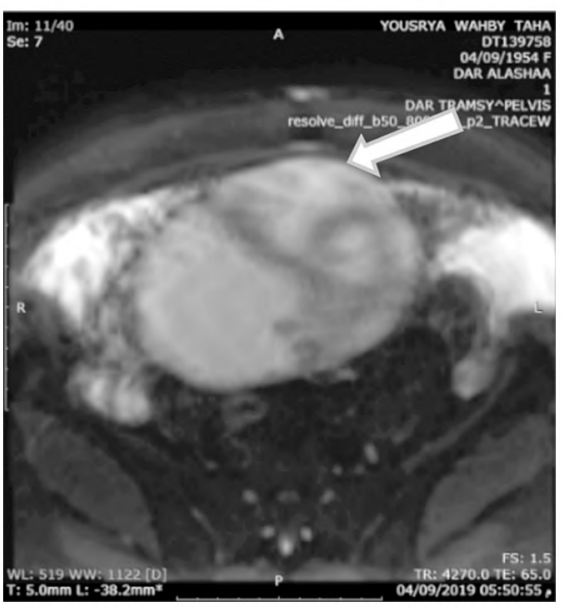

(F)

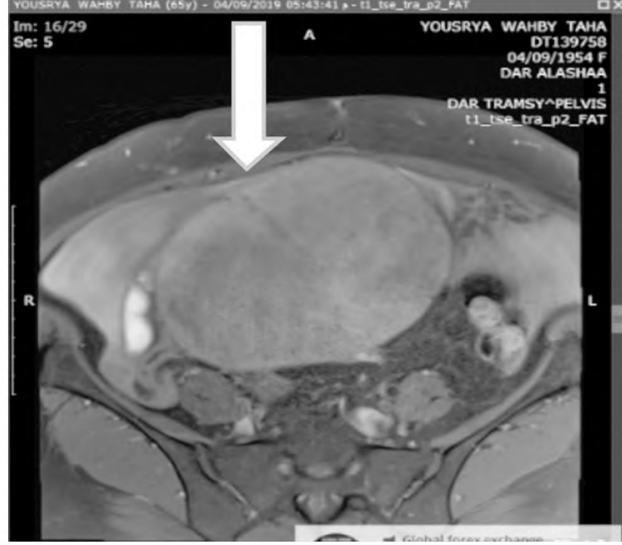

(E)

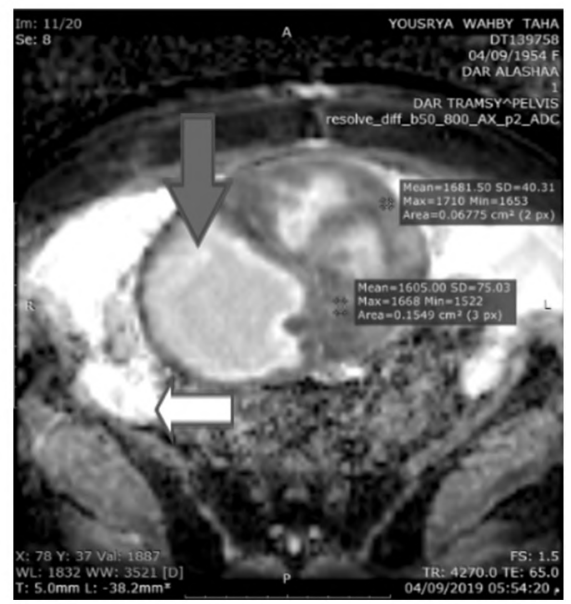

(G)

Fig. (1): 65 years old female complaining of increasing abdominal pain that began in the periumbilical region and then localized to the right lower quadrant. Physical examination tenderness in the right lower quadrant. Results of laboratory studies showed a markedly elevated level of cancer antigen, at $351 \mathrm{U} / \mathrm{mL}$ (normal range, 0-34 U/mL). MRI examination showed (A) Axial T 1 WI showed right ovarian mltilocular complex cystic lesion, the cystic component shows $\mathrm{T} 1$ hypointense signal intensity (white arrow) (B) Axial T2WI shows right ovarian lesion with T2 hyperintense signal intensity of cystic component diameter with multiple intracystic mural nodules. (C,D) Coronal and sagittal T2WI shows a right ovarian lesion with T2 hyperintense signal. (E) Axial T 1 WI postcontrast with fat suppression where the solid nodules show moderate enhancement. (F) DWI where the solid nodules shows diffusion restriction (G) ADC map shows ADC value of the solid component $\left(0.1 \times 10^{-3} \mathrm{~mm}^{2} / \mathrm{s}\right)(\mathrm{red}$ arrow), ADC of the cystic component $\left(2 \times 10^{-3} \mathrm{~mm}^{2} / \mathrm{s}\right)$ while Omental nodule with diffusion restriction, ADC value $(1.3 \times 10$ ${ }^{3} \mathrm{~mm}^{2}$ ) (white arrow). Histopathology revealed papillary serous carcinoma of right ovary high grade with rupture capsule and extension to the external surface. Omental tumor deposits of epithelial invasive type. 




(A)

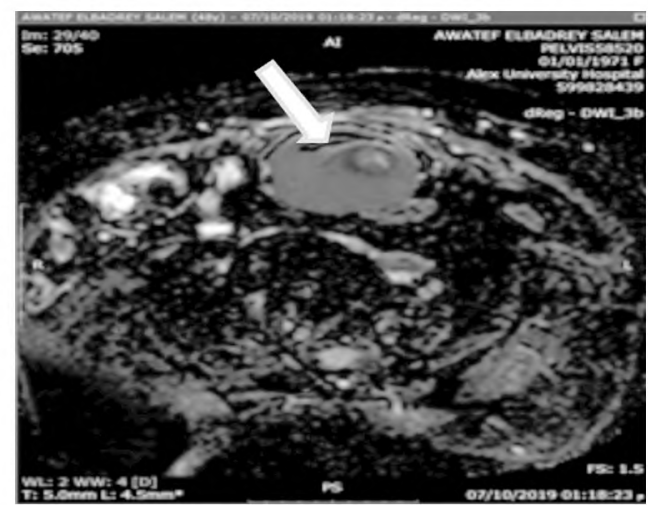

(D)

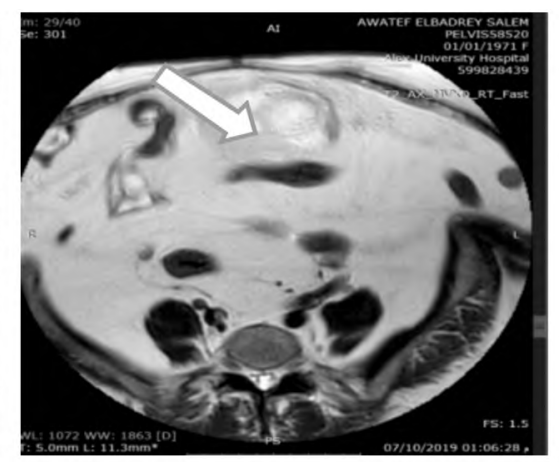

(B)

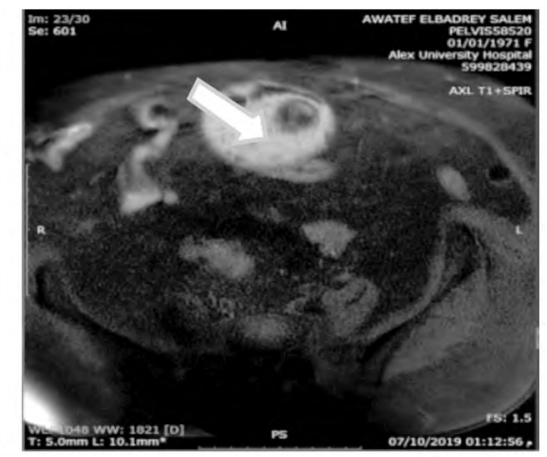

(C)

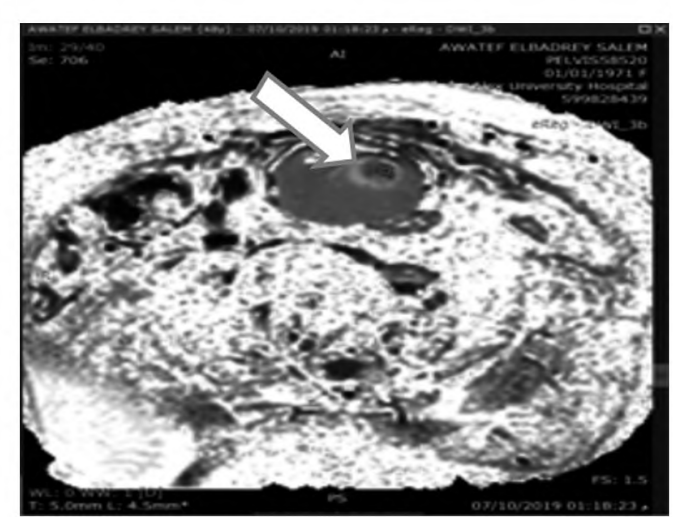

(E)

Fig. (2): 47 years old female patient presented with a complaint of swelling and pain of right lower abdomen for the last two months, no previous history of any illness. Serum alpha-fetoprotein (AFP) and beta-human chorionic gonadotropin (HCG) levels were normal. MRI examination shows (A) T1WI axial cut shows right ovarian cyst measuring about $(11 \times 7.5 \mathrm{~cm})$ showing hypointense signal intensity of cystic component with solid nodule of very high signal intensity (red arrow) (B) T2WI shows mixed hyperintense signal intensity (C) T $1 \mathrm{~W} 1$ post-contrast with fat suppression showing suppression of the solid nodule denoting its fatty nature. (white arrow). (D) DWI shows no diffusion restriction (white arrow), (E) on ADC map ADC of solid component $\left(1.5 \times 10^{-3} \mathrm{~mm}^{2} / \mathrm{s}\right)$ while ADC of cystic component $\left(1.9 \times 10^{-3} \mathrm{~mm}^{2} / \mathrm{s}\right)$. Histopathology revealed right mature cystic teratoma neither immature element nor malignancy can be detected.

Table (10) showed ROC curve analysis to predict the accuracy of MRI contrast study regarding enhancing mass, enhancing septation, enhancing wall, and enhancing nodule in the characterization of ovarian masses compared with histopathology.

ROC curve analysis to predict the accuracy of DWI in the characterization of ovarian masses compared with histopathology showed that the accuracy to predict borderline and benign were $82.6 \%$ with sensitivity and specificity of $83.3 \%$ and $82.4 \%$ respectively. While the accuracy to predict borderline and malignant were $66.7 \%$ with sensitivity and specificity of $91.7 \%$ and $16.7 \%$ respectively. Also, the accuracy in predicting malignant and benign was $86.2 \%$ with sensitivity and specificity of $91.7 \%$ and $82.4 \%$ respectively (Table 11).

ROC curve analysis to predict the accuracy of ADC of the Solid component in characterization of ovarian masses compared with histopathology shows that the accuracy to predict borderline and benign was $63.3 \%$ with sensitivity and specificity of $66.7 \%$ and $60 \%$ respectively. While the accuracy to predict borderline and malignant was $77.8 \%$ with sensitivity and specificity of $88.9 \%$ and $80 \%$ respectively. Also, the accuracy in predicting malignant and benign was $88.9 \%$ with sensitivity and specificity of $88.9 \%$ and $100 \%$ respectively (Table 12).

ROC curve analysis to predict the accuracy of $\mathrm{ADC}$ of the cystic component in characterization of ovarian masses compared with histopathology show that the accuracy in predicting borderline and benign was $54.9 \%$ with sensitivity and specificity of $64.2 \%$ and $52.9 \%$ respectively. While the accuracy to predict borderline and malignant was $61.7 \%$ with sensitivity and specificity of $40.0 \%$ and $83.3 \%$ respectively. Also, the accuracy in predicting malignant and benign was $68.2 \%$ with sensitivity and specificity of $50.0 \%$ and $64.7 \%$ respectively (Table 13). 


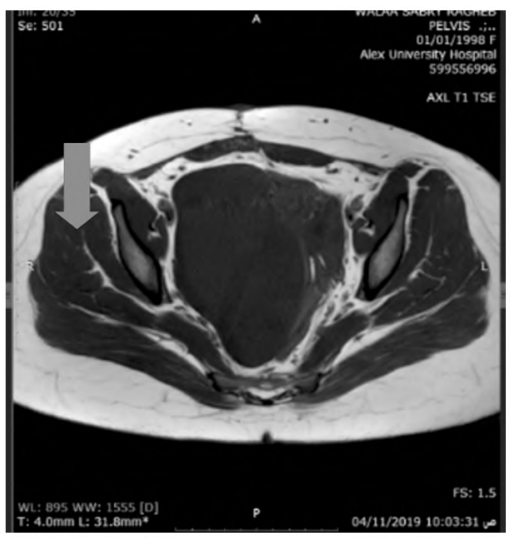

(A)



(B)

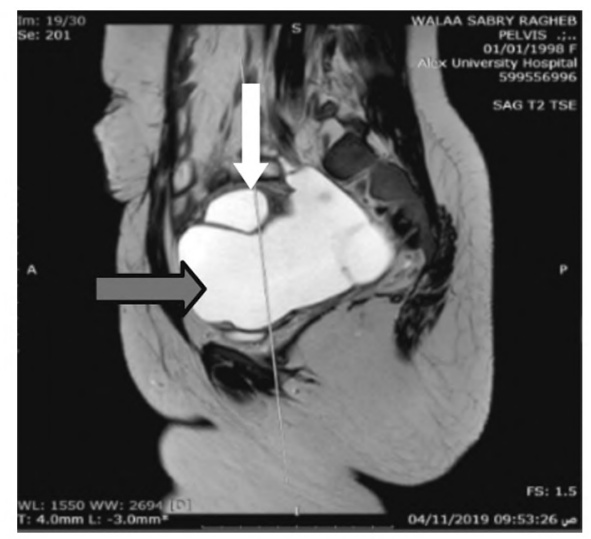

(C)

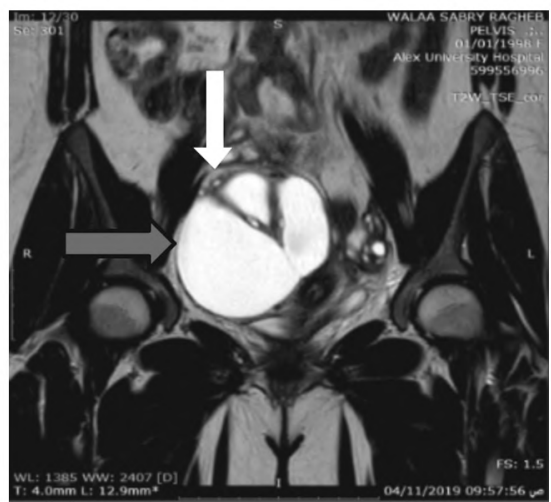

(D)

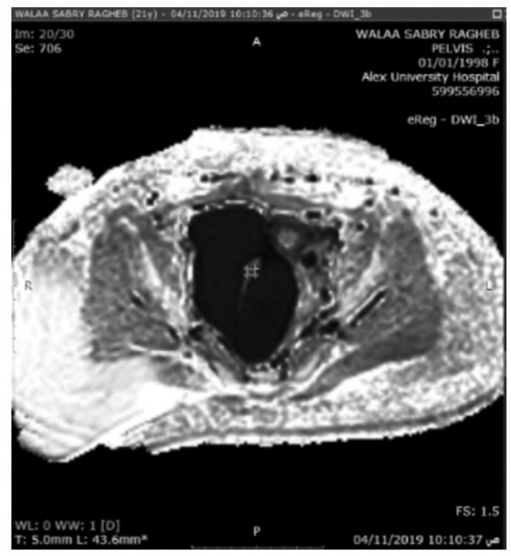

(F)

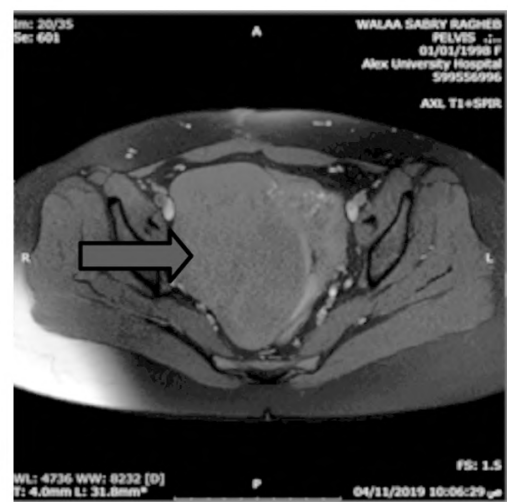

(E)

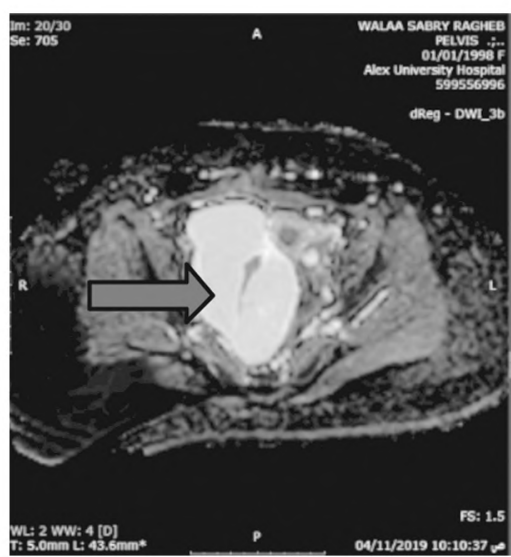

(G)

Fig. (3): 21-years-old female Patient with a history of surgical excision of right ovarian serous cyst-adenoma. MRI examination shows (A) T1WI axial cut shows right para-ovarian multilocular collection with T1 isointense (B,C,D) T2WI axial, sagittal, and coronal show right ovary is seen bulky harboring a T2 hyperintense unilocular cyst (white arrow) and right para-ovarian multilocular T2 hyperintense collection showing thin internal septations which Incasing the right ovary and extending to the Doglous pouch (red arrow). (E) T1WI FS postcontrast showing no contrast enhancement of the collection. (F,G) DWI shows no diffusion restriction \& on the ADC map ADC value of the cystic component $\left(1.4 \times 10^{-3} \mathrm{~mm}^{2} / \mathrm{s}\right)$. Histopathology: Right ovarian and para-ovarian cyst. 
Table (7): Comparison between different histopathological types according to conventional MRI and diffusion-weighted MRI.

\begin{tabular}{|c|c|c|c|c|c|c|c|c|}
\hline \multirow{3}{*}{ MRI } & \multicolumn{6}{|c|}{ Histopathological classification } & \multirow{2}{*}{\multicolumn{2}{|c|}{$\begin{array}{l}\text { Chi-square } \\
\text { test }\end{array}$}} \\
\hline & \multicolumn{2}{|c|}{$\begin{array}{l}\text { Benign } \\
(\mathrm{n}=17)\end{array}$} & \multicolumn{2}{|c|}{$\begin{array}{l}\text { Borderline } \\
\quad(\mathrm{n}=6)\end{array}$} & \multicolumn{2}{|c|}{$\underset{(n=12)}{\text { Malignant }}$} & & \\
\hline & No. & $\%$ & No. & $\%$ & No. & $\%$ & $x^{2}$ & $p$-value \\
\hline \multicolumn{9}{|l|}{$\begin{array}{l}\text { Conventional MRI: } \\
\text { T1 Fat sat.: }\end{array}$} \\
\hline No Supression & 12 & 70.6 & 6 & 100.0 & 12 & 100.0 & 6.176 & $0.046^{*}$ \\
\hline Supression & 5 & 29.4 & 0 & 0.0 & 0 & 0.0 & & \\
\hline \multicolumn{9}{|l|}{ Contrast study: } \\
\hline Enhancing Mass & 0 & 0.0 & 3 & 50.0 & 7 & 58.3 & 13.358 & $<0.001 * *$ \\
\hline Enhancing Septation & 5 & 29.4 & 2 & 33.3 & 10 & 83.3 & 8.861 & $0.012 *$ \\
\hline Enhaning Wall & 2 & 11.8 & 5 & 83.3 & 11 & 91.7 & 20.930 & $<0.001 * *$ \\
\hline Enhancing Nodule & 0 & 0.0 & 3 & 50.0 & 7 & 58.3 & 13.358 & $<0.001 * *$ \\
\hline \multicolumn{9}{|l|}{ Diffusion-weighted MR I: } \\
\hline Restricted Diffusion & 3 & 17.6 & 5 & 83.3 & 11 & 91.7 & 8.296 & $0.025^{*}$ \\
\hline No Restricted Diffusion & 14 & 82.4 & 1 & 16.7 & 1 & 8.3 & & \\
\hline \multicolumn{9}{|c|}{$\mathrm{x}^{2}$ : Chi-square test. $\quad * p$-value $<0.05 \mathrm{~S} . * * * p$-value $<0.001 \mathrm{HS}$. } \\
\hline \multicolumn{9}{|c|}{ Table (8): Comparison between different histopathological types according to ADC value $\left(\times 10^{-3} \mathrm{~mm}^{2} / \mathrm{s}\right)$ of the Solid Component. } \\
\hline & & & $\begin{array}{l}\text { Benign } \\
(\mathrm{n}=17)\end{array}$ & & & $\begin{array}{c}\text { Malignant } \\
(\mathrm{n}=12)\end{array}$ & ANOVA & $p$-value \\
\hline \multicolumn{9}{|c|}{ ADC value of the solid component $\left(\times 10^{-3} \mathrm{~mm}^{2} / \mathrm{s}\right)$ : } \\
\hline Mean \pm SD & & & $1.15 \pm 0.25$ & & .15 & $0.89 \pm 0.26$ & 3.499 & $0.038 *$ \\
\hline Range & & & $0.74-1.4$ & & & $0.6-1.5$ & & \\
\hline \multicolumn{9}{|c|}{ ADC of the cystic component $\left(x 10^{-3} \mathrm{~mm}^{2} / \mathrm{s}\right)$ : } \\
\hline Mean \pm SD & & & $1.88 \pm 0.49$ & & .35 & $1.58 \pm 0.46$ & 1.381 & 0.267 \\
\hline Range & & & $0.80-2.80$ & & 50 & $0.80-2.10$ & & \\
\hline
\end{tabular}

F-One Way Analysis of Variance. $\quad * p$-value $<0.05 \mathrm{~S} . \quad{ }^{* *} p$-value $<0.001 \mathrm{HS}$.

Table (9): Diagnostic performance of conventional MRI (T1 Fat Sat) in the characterization of ovarian masses compared with histopathology.

\begin{tabular}{|c|c|c|c|c|c|c|}
\hline \multirow{3}{*}{ MRI T1 Fat Sat. } & \multicolumn{6}{|c|}{ Histopathological classification } \\
\hline & \multicolumn{2}{|c|}{$\begin{array}{l}\text { Benign } \\
(\mathrm{n}=17)\end{array}$} & \multicolumn{2}{|c|}{$\begin{array}{l}\text { Borderline } \\
\quad(n=6)\end{array}$} & \multicolumn{2}{|c|}{$\begin{array}{c}\text { Malignant } \\
(\mathrm{n}=12)\end{array}$} \\
\hline & No. & $\%$ & No. & $\%$ & No. & $\%$ \\
\hline No Suppression & 12 & 70.6 & 6 & 100.0 & 12 & 100.0 \\
\hline \multirow[t]{2}{*}{ Suppression } & 5 & 29.4 & 0 & 0.0 & 0 & 0.0 \\
\hline & \multicolumn{2}{|c|}{$\begin{array}{c}\text { Borderline \& } \\
\text { Benign }\end{array}$} & \multicolumn{2}{|c|}{$\begin{array}{c}\text { Borderline \& } \\
\text { Malignant }\end{array}$} & \multicolumn{2}{|c|}{$\begin{array}{c}\text { Malignant \& } \\
\text { Benign }\end{array}$} \\
\hline Sensitivity & \multicolumn{2}{|c|}{$100.0 \%$} & \multicolumn{2}{|c|}{$100.0 \%$} & \multicolumn{2}{|c|}{$100.0 \%$} \\
\hline Specificity & \multicolumn{2}{|c|}{$29.4 \%$} & \multicolumn{2}{|c|}{-} & \multicolumn{2}{|c|}{$29.4 \%$} \\
\hline Positive predictive value & \multicolumn{2}{|c|}{$33.3 \%$} & \multicolumn{2}{|c|}{$100.0 \%$} & \multicolumn{2}{|c|}{$50.0 \%$} \\
\hline Negative predictive value & \multicolumn{2}{|c|}{$100.0 \%$} & \multicolumn{2}{|c|}{-} & \multicolumn{2}{|c|}{$100.0 \%$} \\
\hline Accuracy & \multicolumn{2}{|c|}{$47.8 \%$} & \multicolumn{2}{|c|}{$100.0 \%$} & \multicolumn{2}{|c|}{$58.6 \%$} \\
\hline
\end{tabular}


Table (10): Diagnostic performance of conventional MRI (Contrast Study) in the characterization of ovarian masses compared with histopathology.

\begin{tabular}{|c|c|c|c|c|c|c|c|c|c|c|c|c|}
\hline \multirow{3}{*}{\multicolumn{2}{|c|}{ MRI Contrast Study }} & \multicolumn{11}{|c|}{ Histopathological classification } \\
\hline & & \multicolumn{4}{|c|}{$\begin{array}{l}\text { Benign } \\
(\mathrm{n}=17)\end{array}$} & \multicolumn{4}{|c|}{$\begin{array}{l}\text { Borderline } \\
\quad(n=6)\end{array}$} & \multicolumn{3}{|c|}{$\begin{array}{l}\text { Malignant } \\
(\mathrm{n}=12)\end{array}$} \\
\hline & & & No. & $\%$ & & & No. & $\%$ & & & To. & $\%$ \\
\hline \multirow{4}{*}{\multicolumn{2}{|c|}{$\begin{array}{l}\text { Enhancing Mass } \\
\text { Enhancing septation } \\
\text { Enhancing Wall } \\
\text { Enhancing Nodule }\end{array}$}} & & 0 & 0.0 & & & 3 & 50.0 & & & 7 & 58.3 \\
\hline & & & 5 & 29.4 & & & 2 & 33.3 & & & 10 & 83.3 \\
\hline & & & 2 & 11.8 & & & 5 & 83.3 & & & 11 & 91.7 \\
\hline & & & 0 & 0.0 & & & 3 & 50.0 & & & 7 & 58.3 \\
\hline & \multicolumn{4}{|c|}{ Borderline \& Benign } & \multicolumn{4}{|c|}{ Borderline \& Malignant } & \multicolumn{4}{|c|}{ Malignant \& Benign } \\
\hline & 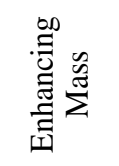 & 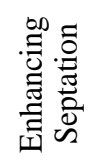 &  & 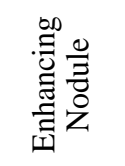 & 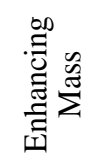 & 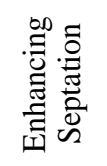 & 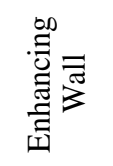 & 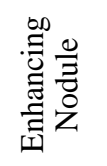 &  & 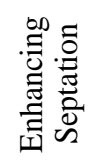 & 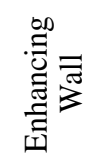 & 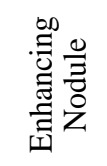 \\
\hline Sensitivity & $50.0 \%$ & $33.3 \%$ & $83.3 \%$ & $50.0 \%$ & $58.3 \%$ & $83.3 \%$ & $91.7 \%$ & $58.3 \%$ & $58.3 \%$ & $83.3 \%$ & $91.7 \%$ & $58.3 \%$ \\
\hline Specificity & $100.0 \%$ & $70.6 \%$ & $88.2 \%$ & $100.0 \%$ & $50.0 \%$ & $66.7 \%$ & $16.7 \%$ & $50.0 \%$ & $100.0 \%$ & $70.6 \%$ & $88.2 \%$ & $100.0 \%$ \\
\hline $\begin{array}{l}\text { Positive } \\
\text { predictive } \\
\text { value }\end{array}$ & $100.0 \%$ & $28.6 \%$ & $71.4 \%$ & $100.0 \%$ & $70.0 \%$ & $83.3 \%$ & $68.8 \%$ & $70.0 \%$ & $100.0 \%$ & $66.7 \%$ & $84.6 \%$ & $100.0 \%$ \\
\hline $\begin{array}{l}\text { Negative } \\
\text { predictive } \\
\text { value }\end{array}$ & $85.0 \%$ & $75.0 \%$ & $93.8 \%$ & $85.0 \%$ & $37.5 \%$ & $66.7 \%$ & $50.0 \%$ & $37.5 \%$ & $77.3 \%$ & $85.7 \%$ & $93.8 \%$ & $77.3 \%$ \\
\hline Accuracy & $87.0 \%$ & $60.9 \%$ & $87.0 \%$ & $87.0 \%$ & $55.6 \%$ & $77.8 \%$ & $66.7 \%$ & $55.6 \%$ & $82.8 \%$ & $75.9 \%$ & $89.7 \%$ & $82.8 \%$ \\
\hline
\end{tabular}

Table (11): Diagnostic performance of DWI in differentiating benign, borderline, and malignant ovarian masses.

\begin{tabular}{|c|c|c|c|c|c|c|}
\hline \multirow{3}{*}{ MRI Diffusion-weighted } & \multicolumn{6}{|c|}{ Histopathological classification } \\
\hline & \multicolumn{2}{|c|}{$\begin{array}{l}\text { Benign } \\
(\mathrm{n}=17)\end{array}$} & \multicolumn{2}{|c|}{$\begin{array}{l}\text { Borderline } \\
\quad(\mathrm{n}=6)\end{array}$} & \multicolumn{2}{|c|}{$\begin{array}{l}\text { Malignant } \\
(\mathrm{n}=12)\end{array}$} \\
\hline & No. & $\%$ & No. & $\%$ & No. & $\%$ \\
\hline Restricted Diffusion & 3 & 17.6 & 5 & 83.3 & 11 & 91.7 \\
\hline \multirow[t]{2}{*}{ No Restricted Diffusion } & 14 & 82.4 & 1 & 16.7 & 1 & 8.3 \\
\hline & \multicolumn{2}{|c|}{$\begin{array}{c}\text { Borderline \& } \\
\text { Benign }\end{array}$} & \multicolumn{2}{|c|}{$\begin{array}{c}\text { Borderline \& } \\
\text { Malignant }\end{array}$} & \multicolumn{2}{|c|}{$\underset{\text { Menign }}{\text { Malignant \& }}$} \\
\hline Sensitivity & \multicolumn{2}{|c|}{$83.3 \%$} & \multicolumn{2}{|c|}{$91.7 \%$} & \multicolumn{2}{|c|}{$91.7 \%$} \\
\hline Specificity & \multicolumn{2}{|c|}{$82.4 \%$} & \multicolumn{2}{|c|}{$16.7 \%$} & \multicolumn{2}{|c|}{$82.4 \%$} \\
\hline Positive predictive value & \multicolumn{2}{|c|}{$62.5 \%$} & \multicolumn{2}{|c|}{$68.8 \%$} & \multicolumn{2}{|c|}{$78.6 \%$} \\
\hline Negative predictive value & \multicolumn{2}{|c|}{$93.3 \%$} & \multicolumn{2}{|c|}{$50.0 \%$} & \multicolumn{2}{|c|}{$93.3 \%$} \\
\hline Accuracy & \multicolumn{2}{|c|}{$82.6 \%$} & \multicolumn{2}{|c|}{$66.7 \%$} & \multicolumn{2}{|c|}{$86.2 \%$} \\
\hline
\end{tabular}


Table (12): Diagnostic performance and accuracy of ADC value of the solid component in characterization of ovarian masses in different histopathological types.

\begin{tabular}{lccc}
\hline $\begin{array}{l}\text { ADC value }\left(\times 10^{-3} \mathrm{~mm}^{2} / \mathrm{s}\right) \text { of } \\
\text { the Solid Component }\end{array}$ & $\begin{array}{c}\text { Benign } \\
(\mathrm{n}=17)\end{array}$ & $\begin{array}{c}\text { Borderline } \\
(\mathrm{n}=6)\end{array}$ & $\begin{array}{c}\text { Malignant } \\
(\mathrm{n}=12)\end{array}$ \\
\hline Mean $\pm \mathrm{SD}$ & $1.15 \pm 0.25$ & $1.27 \pm 0.15$ & $0.89 \pm 0.26$ \\
\hline & $\begin{array}{c}\text { Borderline \& } \\
\text { Benign }\end{array}$ & $\begin{array}{c}\text { Borderline \& } \\
\text { Malignant }\end{array}$ & $\begin{array}{c}\text { Malignant \& } \\
\text { Benign }\end{array}$ \\
\hline Cut-off & $\leq 1.2$ & $\leq 1$ & $\leq 1$ \\
Sensitivity & $66.7 \%$ & $88.9 \%$ & $88.9 \%$ \\
Specificity & $60 \%$ & $80 \%$ & $100 \%$ \\
Positive predictive value & $50 \%$ & $88.9 \%$ & $100 \%$ \\
Negative predictive value & $75 \%$ & $80 \%$ & $75 \%$ \\
Accuracy & $63.3 \%$ & $77.8 \%$ & $88.9 \%$ \\
\hline
\end{tabular}

Table (13): Sensitivity, specificity, PPV, NPV, and overall accuracy of ADC of the cystic component in characterization of ovarian masses compared with histopathology.

\begin{tabular}{lccc}
\hline $\begin{array}{l}\text { ADC of the cystic component } \\
\left(\mathrm{x} 10^{-3} \mathrm{~mm}^{2} / \mathrm{s}\right)\end{array}$ & $\begin{array}{c}\text { Benign } \\
(\mathrm{n}=17)\end{array}$ & $\begin{array}{c}\text { Borderline } \\
(\mathrm{n}=6)\end{array}$ & $\begin{array}{c}\text { Malignant } \\
(\mathrm{n}=12)\end{array}$ \\
\hline Mean $\pm \mathrm{SD}$ & $1.88 \pm 0.49$ & $1.85 \pm 0.35$ & $1.58 \pm 0.46$ \\
\hline & $\begin{array}{c}\text { Borderline \& } \\
\text { Benign }\end{array}$ & $\begin{array}{c}\text { Borderline \& } \\
\text { Malignant }\end{array}$ & $\begin{array}{c}\text { Malignant \& } \\
\text { Benign }\end{array}$ \\
\hline Cut-off & $<1.8$ & $<1.5$ & $<1.6$ \\
Sensitivity & $64.2 \%$ & $40.0 \%$ & $50.0 \%$ \\
Specificity & $52.9 \%$ & $83.3 \%$ & $64.7 \%$ \\
Positive predictive value & $33.3 \%$ & $80.0 \%$ & $45.5 \%$ \\
Negative predictive value & $81.8 \%$ & $45.5 \%$ & $68.8 \%$ \\
Accuracy & $54.9 \%$ & $61.7 \%$ & $68.2 \%$ \\
\hline
\end{tabular}

\section{Discussion}

A reliable method to differentiate benign from malignant ovarian masses would be valuable as it allows for appropriate subspecialty referral, optimal preoperative planning, counselling of the patient, and informing them about possible surgical strategies $[15,16]$.

Magnetic Resonance Imaging (MRI) is an essential problem-solving tool to determine the origin of a pelvic mass and then characterize an adnexal mass, especially in patients with indeterminate lesions $[\mathbf{1 7 , 1 8}]$.

The present study was conducted in 35 patients with an ovarian mass on a previous US examination to determine whether the addition of DW sequences to a conventional MR imaging protocol can predict the nature of suspicious ovarian masses detected previously by conventional ultrasound.

In the present study, the mean patient age was $41.00 \pm 13.37$ years, which disagreed with Alahwal et al., [19] study that carried on 82 female patients concluded that the mean patient age was $51.52 \pm$ 11.31 years.
In our study, pelvi-abdominal pain was the most common complaint of the patients $(91 \%)$, which was in agreement with Liu et al., [20] study which carried on 203 patients who presented with adnexal masses and found that pelvi-abdominal pain was the most common complaint of the patients $(57.7 \%)$.

Also, we found that lesions in the right side were more than the left side $(77.14 \%, 22.86 \%$ respectively) and $37.14 \%$ bilateral lesions, which was in agreement with a study done by Taj-Aldean, [21] which had $62.5 \%$ of the lesions in the right side and $37.5 \%$ in the left side, this agreement was a mere coincidence.

In the current study, 17 (48.57\%) of 35 ovarian masses were benign, and 12 (34.29\%) were malignant, and $6(17.14 \%)$ were borderline, these results were similar to the study of Alahwal et al., [19] who found that Thirty-six (43.9\%) of the 82 ovarian masses were benign, and $41(50 \%)$ were malignant, and 5 cases $(6.1 \%)$ were borderline.

Histopathological examination revealed that the most common benign lesion was the mature 
cystic teratomas, which was diagnosed in 5 (14.29\%) patients, followed by mucinous cystadenoma in two $(5.71 \%)$ patients, and endometrioma, also in two $(5.71 \%)$ patient.

In a study done by Shadab et al., [22] two hundred sixty-seven ovarian masses undergo a histopathological examination. Of these, $163(61.0 \%)$ were tumor-like, $96(36.0 \%)$ were benign tumors and $8(3.0 \%)$ were malignant. The most common tumor-like condition was the Corpus luteum cyst (43.4\% cases). Among the benign and malignant tumors, mature cystic teratoma ( $17.2 \%$ of total) and Epithelial tumors $(n=4)$ were the most common. There is a statistically significant positive relation between age and various ovarian masses $(p=0.002)$.

In the current study, $5.9 \%$ ( 1 of 17 ) benign cases showed solid component and 50.0\% (6 of 12) malignant cases showed solid component $(p<0.05)$, which was in agreement with Li et al., [23] study which concluded that solid components were found in $11 / 46(23.9 \%)$ benign and $37 / 85$ $(43.5 \%)$ malignant masses $(p<0.05)$. (5/12) $41.7 \%$ of malignant cases were cystic and (6/12) $50.0 \%$ of malignant cases were mixed cystic and solid, but $16.7 \%$ only $(2 / 12)$ of malignant cases were solid only.

This was in agreement with a previous study by Taj-Aldean, [21] where histopathological findings of benign and malignant lesions revealed that out of 80 patients confirmed with surgery and histological evaluation, $64(80 \%)$ of them were benign and $16(20 \%)$ patients had malignant masses distributed as follow (1/16 (6\%) was solid only, solidcystic in $13 / 16(81.25 \%)$, and cystic only in $2 / 16$ $(12.5 \%)$. Only $5.9 \%(1 / 17)$ of benign cases are complex, with a statistically significant difference ( $p$-value <0.05).

The current study showed $70.6 \%$ of the benign lesions were unilocular, while none of the malignant lesions were unilocular. This agreed with Foti et al., [5] who reported that the unilocular cystic masses in the adnexal region are more likely benign.

In the present study, the conventional MRI T2WI found that $70.6 \%(12 / 17)$ of benign cases showed a high signal in T2WI. In comparison, only $41.7 \%(5 / 12)$ of malignant lesions showed high signal in T2WI images. This disagreed with Zhang et al., [16] study, which found that $52.7 \%$ of the studied benign lesions (39/74) showed high signal in T2WI while $84.3 \%$ of studied malignant lesions (108/128) showed high signal in T2 weighted images. It could be attributed to our more con- siderable number of benign cases than malignant ones.

In the present study regarding Fat suppression sequence, $29.4 \%(5 / 12)$ of benign cases showed fat density, but none of the borderline or malignant cases showed fat, which was statistically significant ( $p$-value 0.05). While concerning the vegetation and papillary projections, $100 \%$ of benign cases have no vegetations or papillary projections, 3 of $6(50.0 \%)$ of borderline lesions, and 3 of $12(25.0 \%)$ of malignant cases showed papillary projections, which recorded a statistically significant difference ( $p$-value $<0.05)$. Also, the mean width of malignant lesions $(27.70 \mathrm{~cm})$ was larger than in benign lesions $(15.99 \mathrm{~cm})$, with no statistically significant difference as the $p$-value was 0.485 .

Considering the contrast enhancement pattern, the present study showed that $85.7 \%$ of heterogeneously enhanced lesions were malignant (6 out of 7 cases), $83.3 \%$ of malignant cases show enhancing septations.

In coordinance with Taj-Aldean, [21] lesions considered malignant should have complex solidcystic components, vegetation on the wall, and the lesion's large size heterogeneous enhancement, and septa presence inside the cystic adnexal lesion, the presence of ascites, and peritoneal invasion.

Regarding DWI, the qualitative assessment of diffusion restriction was done by visual assessment for the presence of hyperintensity in b800 images and hypointensity in the corresponding ADC images. $91.7 \%$ of malignant lesions in the study (1 1 from a total of 12 malignant lesions) showed restricted diffusion with low ADC values. This agreed with Rajasri et al., [24] study, which carried on 112 female patients with initial undetermined complex adnexal masses referred for MRI based on ultrasound findings for further characterization and staging. They concluded that an adnexal mass with restricted diffusion usually is a malignant lesion. This finding, that of high signal intensity on DWI in solid components, may reduce both the extracellular matrix and the diffusion space of water protons in the extracellular and intracellular dimensions due to an increased nuclear to cytoplasmic ratio and hypercellularity. However, the low signal intensity on DWI in benign ovarian tumors such as fibrothecomas, cystadenofibromas, and Brenner tumors, may be due to the high density of fibers, the low cellularity.

Qualitative DWI, in the present study, Hyperintense signal on DWI was observed in 11/12 
(91.7\%) of malignant, 5 of $6(83.3 \%)$ of borderline tumors, and in only $3 / 17(17.6 \%)$ of the benign lesions $(p<0.05)$. The restricted diffusion in the solid components had a sensitivity of $91.7 \%$, specificity $82.4 \%$, PPV $78.6 \%$, and NPV of $93.3 \%$ with overall accuracies of $86.2 \%$.

In the current study, we had 17 pathologically proven benign ovarian lesions, 14 cases showed facilitated diffusion, and 3 cases of the rest 17 cases are two tub ovarian abscess and chocolate cyst (endometriomas) showed restricted diffusion due to high hemosiderin and pus content.

This was in agreement with Nasr et al., [25] study which conducted on 30 cases of different ovarian lesions. Thirty-two cases were pathologically proved (classified to 12 benign and $11 \mathrm{ma}-$ lignant), seven cases showed facilitated diffusion (low signal in diffusion images, high signal on corresponding ADC map and high ADC values), five hemorrhagic cysts (diagnosed by MRI criteria and follow-up U/S) and two endometriomas (proved pathologically) showed high signal not only on diffusion images but also on corresponding ADC map and ADC values.

Kim et al., [26] in a meta-analysis review of 21 studies, concluded that DWI could not differentiate between benign and malignant ovarian masses. In a recent literature review.

In the present study, the cystic component's mean ADC value did not differ significantly between benign and malignant masses ( $p=0.267)$. It was $1.88 \pm 0.49 \mathrm{~mm}^{2} / \mathrm{s}$ for benign tumors, $1.85 \pm 0.35$ for borderline lesions, and $1.58 \pm 0.46 \times 10^{-3} \mathrm{~mm}^{2} / \mathrm{s}$ for malignant tumors, which also considered statistically insignificant.

This was in agreement with $\mathrm{Li}$ et al., [23] who carried out a study on 127 patients with pelvic masses ( 46 benign and 85 malignant). The purpose of this study was to evaluate differences in ADC values for differentiating benign versus malignant ovarian tumors preoperatively. They concluded that the mean ADC value of the cystic component $=2.58 \times 10^{-3} \pm 0.27 \times 10^{-3} \mathrm{~mm}^{2} / \mathrm{s}$ for benign tumors, and $2.44 \times 10^{-3} \pm 0.33 \times 10^{-3} \mathrm{~mm}^{2} / \mathrm{s}$ for malignant tumors which found to be statistically insignificant.

In the current study, the cystic component's DWI and ADC values were less valuable and less accurate in differentiation between benign and malignant masses, with considerable overlap in $A D C$ value. These findings have been observed in previous studies $[\mathbf{1 0 , 2 3 ]}$.
On the other hand, we found that the mean ADC value of the solid component can differ significantly between benign and malignant masses $(p<0.05)$ as it was $1.15 \pm 0.25 \times 10^{-3} \mathrm{~mm}^{2} / \mathrm{s}$ for benign tumors, $1.27 \pm 0.15 \times 10^{-3} \mathrm{~mm}^{2} / \mathrm{s}$ for borderline tumors and $0.89 \pm 0.26 \times 10^{-3} \mathrm{~mm}^{2} / \mathrm{s}$ for malignant tumors which also considered statistically significant which was in agreement with $\mathrm{Li}$ et al., [23] study which concluded that DWI is beneficial for differentiating between benign and malignant ovarian lesions regarding to solid components as they found that the mean ADC value of the solid component $=1.69 \times 10^{-3} \pm 0.25 \times 10^{-3} \mathrm{~mm}^{2} / \mathrm{s}$ for benign tumors, and $1.03 \times 10^{-3} \pm 0.22 \times 10^{-3} \mathrm{~mm}^{2} / \mathrm{s}$ for malignant tumors which found to be statistically significant.

Also, the current study showed the sensitivity, specificity, PPV, NPV, and accuracy of conventional MR imaging all have increased from $87.5 \%, 86.4$, $70 \%, 95 \%, 86.7 \%$ respectively for conventional MRI to $88.9 \%, 100 \%, 100 \%, 75 \%, 88.9 \%$ respectively for DWI according to ADC values of the solid components. In agreement with Li et al., [23] study concluded that the sensitivity, specificity, PPV, NPV, and accuracy of conventional MR imaging all have increased after adding DWI to the conventional MRI.

In the present study, we found that ADC value $<1 \times 10^{-3} \mathrm{~mm}^{2} / \mathrm{s}$ may be the optimal cut off for differentiating between benign and malignant masses, which was in agreement with Zhang et al., [16] study carried on 191 female patients with different ovarian lesions underwent diffusion-weighted (DW) magnetic resonance (MR) imaging of 202 ovarian masses aiming to evaluate the role of DWI in differentiating between benign and malignant ovarian lesions, they concluded that ADC value $\geq 1.20$ $\mathrm{x} 10^{-3} \mathrm{~mm}^{2} / \mathrm{s}$ might be the optimal cutoff for differentiating between benign and malignant tumors.

Our results are close to those of Zhuang et al., [27]. They reported mean ADC value for benign masses $1.49 \pm 0.3910^{-3} \mathrm{~mm}^{2} / \mathrm{s}$ and for malignant ovarian masses $0.95 \pm 0.13$ with a statistically significant difference.

Also, Hemat et al., [28] reported an overall accuracy of MRI of $84 \%$, similar to the current study. Based on morphological MRI criteria.

Emad Eldin et al., [29] reported a sensitivity of $94.3 \%$ and an accuracy of $92.3 \%$ in differentiation between benign and malignant ovarian lesions, results higher than the current study. 
In the current study, we studied the added value of quantitative and qualitative DWI in both the ovarian masses' solid and cystic components. We used ADC cut-off value $\geq 1.20 \times 10^{-5} \mathrm{~mm}^{2} / \mathrm{s}$ for differentiation between benign and malignant masses in the current study. This cut-off value was suggested by several previous studies as the best cut-off value [23,30-32]

In the present study, the mean $\mathrm{ADC}$ value for benign masses was $1.52 \pm 0.65 \times 10^{-3} \mathrm{~mm}^{2} / \mathrm{s}$ and for malignant masses $0.97 \pm 0.13 \times 10^{-3} \mathrm{~mm}^{2} / \mathrm{s}$, with a statistically significant difference $(p<0.01)$. Our results are close to those of Zhuang et al., 2019. They reported mean ADC value for benign masses $1.49 \pm 0.3910^{-3} \mathrm{~mm}^{2} / \mathrm{s}$ and for malignant ovarian masses $0.95 \pm 0.13$ with a statistically significant difference.

The solid component's high signal intensity on DWI had a sensitivity of $94.44 \%$ and $92 \%$ accuracy in the current study. The low ADC had a sensitivity of $88.89 \%$ and an accuracy of $88 \%$ in differentiation between benign and malignant masses.

Meng et al., [33] in a systemic meta-analysis of 10 studies included 1159 subjects, of which 559 patients had malignant masses, and 600 had benign masses. They investigated DWI's efficiency in differentiation between benign and malignant masses with a pooled sensitivity of $93 \%$ and a pooled specificity of $89 \%$. Zhang et al., [16] concluded that DWI is an excellent diagnostic tool for discrimination between benign and malignant masses. There was some overlap in the ADC value in the current study between the benign and malignant groups, maybe due to the presence of dense collagen fibers and the presence of fibroblasts in the benign masses decreasing ADC value.

Also, malignant masses may exhibit elevated $\mathrm{ADC}$ value due to the presence of necrosis or cystic changes [34]. The presence of high signal intensity in DWI was the single most accurate criterion for differentiation between benign and malignant masses in the current study. Our results are similar to those of Zhang et al., [16]

The high Signal in the solid component is due to hypercellularity and decreased extracellular space. On the other hand, the low SI in the benign masses is due to low cellularity and high density of fibers [23].

Combined DWI and conventional MRI sequences had the highest accuracy in the current study, with a sensitivity of $95.3 \%$ and accuracy of $93.1 \%$.
Our results similar to Mansour et al., 2015 who reported the sensitivity of combined DWI and MRI $93.3 \%$, but the overall accuracy in their study was less than the current study (82.3\%) [35].

\section{Conclusion:}

According to us, DWI has a sensitivity of $(91 \%)$ but didn't improve the specificity $(82.4 \%)$ or the accuracy $(86.2 \%)$. DWI can help and increase the confidence of MRI in assessment of ovarian masses provided the inclusion of the conventional MRI data, combined analysis of DWI quantitative and qualitative criteria, and finally the awareness of the possible sequence pitfalls.

\section{References}

1- TORRE L.A., TRABERT B., DESANTIS C.E., MILLER K.D., SAMIMI G., RUNOWICZ C.D., GAUDET M.M., JEMAL A. and SIEGEL R.L.: Ovarian cancer statistics, 2018. CA Cancer J. Clin., 68 (4): 284-96, 2018.

2- VALENTINI A.L., GUI B., MICCÒ M., MINGOTE M.C., De GAETANO A.M., NINIVAGGI V. and BONOMO L. Benign and Suspicious Ovarian Masses-MR Imaging Criteria for Characterization: Pictorial Review. Journal of Oncology, 481806, 2012.

3- CHAN J.K., URBAN R., CAPRA A.M., JACOBY V., OSANN K., WHITTEMORE A. and HABEL L.A.: Ovarian cancer rates after hysterectomy with and without salpingo-oophorectomy. Obstet. Gynecol., 123 (1): 6572, 2014.

4- TAKEUCHI M., MATSUZAKI K. and NISHITANI H.: Diffusion-weighted magnetic resonance imaging of ovarian tumors: Differentiation of benign and malignant solid components of ovarian masses. Journal of computer assisted tomography, 34 (2): 173-6, 2010.

5- FOTI P.V., ATTINÀ G., SPADOLA S., CALTABIANO R., FARINA R., PALMUCCI S., ZARBO G., ZARBO R., D'ARRIGO M., MILONE P. and ETTORRE G.C.: MR imaging of ovarian masses: Classification and differential diagnosis. Insights Imaging,7 (1): 21-41, 2016.

6- EL-SAYED E-S., ABDULLAH M. and ALI H.: The role of diffusion-weighted MRI on the differentiation of complex adnexal masses. Menoufia Medical Journal, 32 (3): 881-8, 2019.

7- HORI M., KIM T., ONISHI H., NAKAMOTO A., TSUBOYAMA T., TATSUMI M. and TOMIYAMA N.: Ovarian Masses: MR Imaging with $T<$ sub $>1</$ sub $>$-weighted 3dimensional Gradient-echo IDEAL Water-fat Separation Sequence at 3T. Magnetic Resonance in Medical Sciences, 11 (2): 117-27, 2012.

8- YEOH M.: Investigation and management of an ovarian mass. Australian Family Physician, 44: 48-52, 2015.

9- INADA Y., MATSUKI M., NAKAI G., TATSUGAMI F., TANIKAKE M., NARABAYASHI I., YAMADA T. and TSUJI M.: Body diffusion-weighted MR imaging of uterine endometrial cancer: Is it helpful in the detection of cancer in nonenhanced MR imaging? European Journal of Radiology, 70 (1): 122-7, 2009. 
10- KATAYAMA M., MASUI T., KOBAYASHI S., ITO T., SAKAHARA H., NOZAKI A. and KABASAWA H. Diffusion-weighted echo planar imaging of ovarian tumors: is it useful to measure apparent diffusion coefficients? Journal of computer assisted tomography, 26 (2): 250-6, 2002.

11-KILICKESMEZ O., BAYRAMOGLU S., INCI E., CIMILLI T. and KAYHAN A.: Quantitative diffusion-weighted magnetic resonance imaging of normal and diseased uterine zones. Acta radiologica (Stockholm, Sweden: 1987), 50 (3): 340-7, 2009.

12- WAKEFIELD J.C., DOWNEY K., KYRIAZI S. and deSOUZA N.M.: New MR techniques in gynecologic cancer. AJR American Journal of Roentgenology, 200 (2): 249-60, 2013.

13- KIERANS A.S., BENNETT G.L., MUSSI T.C., BABB J. S., RUSINEK H., MELAMED J. and ROSENKRANTZ A.B.: Characterization of malignancy of adnexal lesions using ADC entropy: Comparison with mean ADC and qualitative DWI assessment. Journal of Magnetic Resonance Imaging, 37 (1): 164-71, 2013.

14- MOTOSHIMA S., IRIE H., NAKAZONO T., KAMURA T. and KUDO S.: Diffusion-weighted MR imaging in gynecologic cancers. J. Gynecol. Oncol., 22 (4): 275-87, 2011.

15- WASNIK A.P., MENIAS C.O., PLATT J.F., LALCHANDANI U.R., BEDI D.G. and ELSAYES K.M.: Multimodality imaging of ovarian cystic lesions: Review with an imaging based algorithmic approach. World Journal of Radiology, 5 (3): 113-25, 2013.

16- ZHANG P., CUI Y., LI W., REN G., CHU C. and WU X.: Diagnostic accuracy of diffusion-weighted imaging with conventional MR imaging for differentiating complex solid and cystic ovarian tumors at $1.5 \mathrm{~T}$. World Journal of Surgical Oncology, 10: 237, 2012.

17- CHILLA B., HAUSER N., SINGER G., TRIPPEL M., FROEHLICH J.M. and KUBIK-HUCH R.A.: Indeterminate adnexal masses at ultrasound: effect of MRI imaging findings on diagnostic thinking and therapeutic decisions. Eur. Radiol., 21 (6): 1301-10, 2011.

18- TOGASHI K.: Ovarian cancer: The clinical role of US, CT, and MRI. Eur. Radiol., 13 (6): L87-L104, 2003.

19- ALAHWAL L., MOHAMED M.H. and DAWOUD F.: Can Quantitative and Qualitative DWI Differentiate between Benign and Malignant Ovarian Masses? The Medical Journal of Cairo University, 88 (March): 91-102, 2020.

20- LIU H., WANG X., LU D., LIU Z. and SHI G.: Ovarian masses in children and adolescents in China: Analysis of 203 cases. Journal of Ovarian Research, 6: 47, 2013.

21- TAJ-ALDEAN K.A.: Validity of Magnetic Resonance Imaging (MRI) in characterizing adnexal masses: A prospective study. Academiaedu, 9 (11.25): 17-25, 2017.

22- SHADAB S. and TADAYON T.: Histopathological diagnosis of ovarian mass. J. Pathol. Nepal., 8 (1): 1261-4, 2018.

23- LI W., CHU C., CUI Y., ZHANG P. and ZHU M.: Diffusion-weighted MRI: A useful technique to discriminate benign versus malignant ovarian surface epithelial tumors with solid and cystic components. Abdominal Imaging, 37 (5): 897-903, 2012.

24- RAJASRI B., H. P. and S. S.: Role of Diffusion Weighted MR Imaging in Adnexal lesions in Female Pelvis A Prospective study. JMSCR, 9 (4): 12675-85, 2016.

25- NASR E., HAMED I., ABBAS I. and KHALIFA N.M.: Dynamic contrast enhanced MRI in correlation with diffusion weighted (DWI) MR for characterization of ovarian masses. EJRNM, 45 (3): 975-85, 2014.

26- KIM H.J., LEE S.Y., SHIN Y.R., PARK C.S. and KIM K.: The Value of Diffusion-Weighted Imaging in the Differential Diagnosis of Ovarian Lesions: A MetaAnalysis. PloS one, 11 (2): e0149465, 2016.

27- ZHUANG Y., WANG T. and ZHANG G.: DiffusionWeighted Magnetic Resonance Imaging (DWI) Parameters in Benign and Malignant Ovarian Tumors with Solid and Cystic Components. Journal of the College of Physicians and Surgeons-Pakistan: JCPSP, 29 (2): 105-8, 2019.

28- HEMAT E.M., K.M. E-G. and A.A I.: Quantitative multiparametric MRI in characterization of ovarian cystic masses. J. Am. Sci., 13 (1): 93-103, 2017.

29- EMAD-ELDIN S., GRACE M.N., WAHBA M.H. and ABDELLA R.M.: The diagnostic potential of diffusion weighted and dynamic contrast enhanced MR imaging in the characterization of complex ovarian lesions. EJRNM, 49 (3): 884-91, 2018.

30- THOMASSIN-NAGGARA I., BAZOT M., DARAÏ E., CALLARD P., THOMASSIN J. and CUENOD C.A.: Epithelial ovarian tumors: Value of dynamic contrastenhanced MR imaging and correlation with tumor angiogenesis. Radiology, 248 (1): 148-59, 2008.

31- TAKEUCHI M., MATSUZAKI K. and NISHITANI H.: Diffusion-weighted magnetic resonance imaging of ovarian tumors: differentiation of benign and malignant solid components of ovarian masses. Journal of computer assisted tomography, 34 (2): 173-6, 2010.

32- THOMASSIN-NAGGARA I., TOUSSAINT I., PERROT N., ROUZIER R., CUENOD C.A., BAZOT M. and DARAÏ E.: Characterization of complex adnexal masses: value of adding perfusion- and diffusion-weighted MR imaging to conventional MR imaging. Radiology, 258 (3): 793-803, 2011.

33- MENG X.F., ZHU S.C., SUN S.J., GUO J.C. and WANG X.: Diffusion weighted imaging for the differential diagnosis of benign vs. malignant ovarian neoplasms. Oncology letters, 11 (6): 3795-802, 2016.

34- FUJII S., KAKITE S., NISHIHARA K., KANASAKI Y., HARADA T., KIGAWA J., KAMINOU T. and OGAWA T.: Diagnostic accuracy of diffusion-weighted imaging in differentiating benign from malignant ovarian lesions. Journal of magnetic resonance imaging: JMRI, 28 (5): 1149-56, 2008.

35- MANSOUR S., WESSAM R. and RAAFAT M.: Diffusionweighted magnetic resonance imaging in the assessment of ovarian masses with suspicious features: Strengths and challenges. The Egyptian Journal of Radiology and Nuclear Medicine, 46 (4): 1279-89, 2015. 


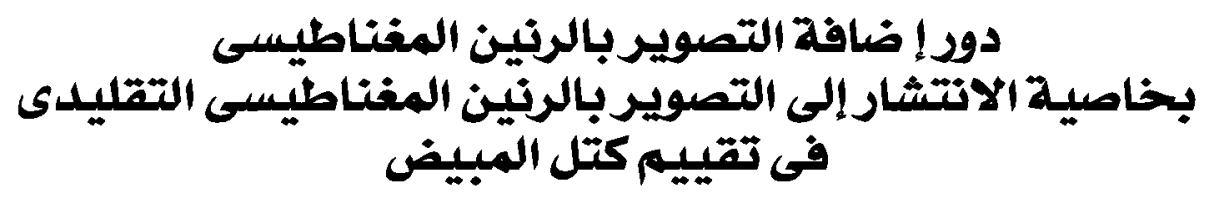

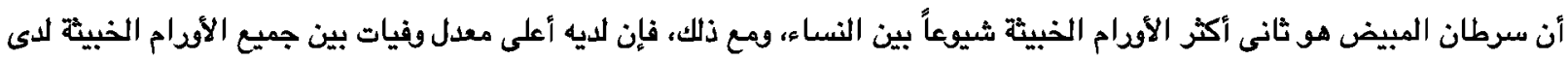

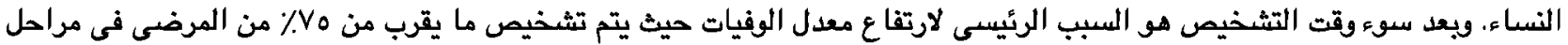

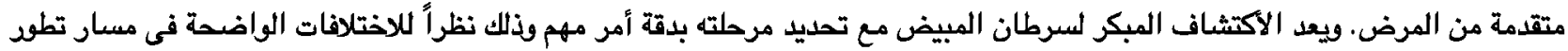

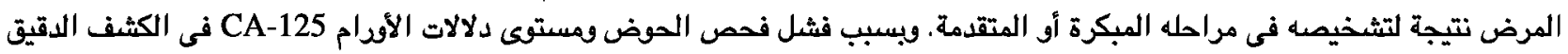


بالرنين المغناطيسى (MR) أمراً يهماً لا غنى عنه لتشخيص أورام المبيض.

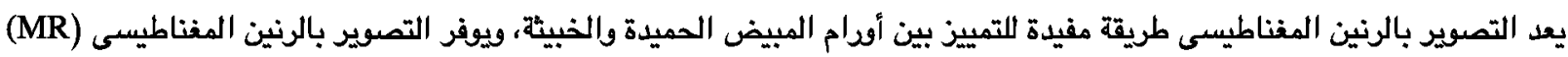

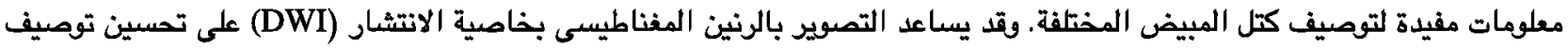
أودام المبيض بالرنين المغناطيسى.

كان الهدف من العمل هو تحديد ما إذا كانت إضافة التصوير بالرنين المغناطيسى بخاصية الانتشار (DWI) إلى بروتوكول التصوير بالرنين

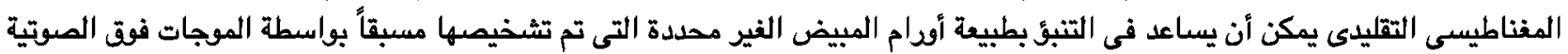
التقليدية.

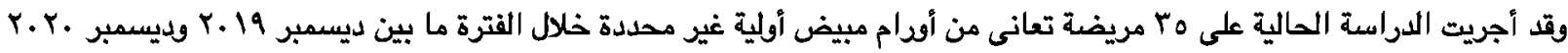

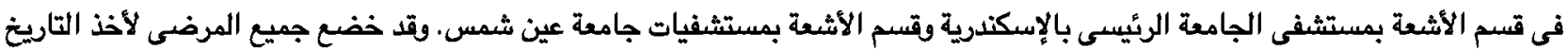

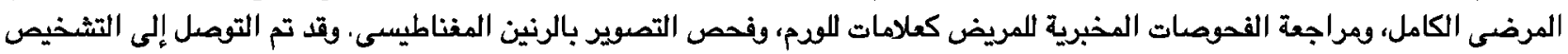

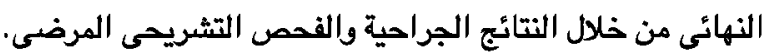

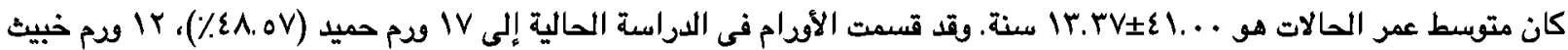

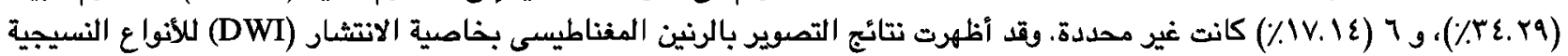

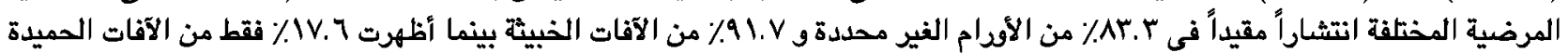

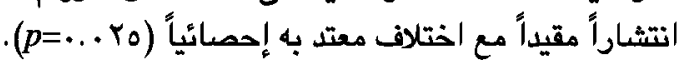

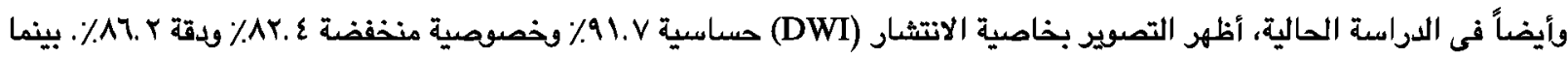

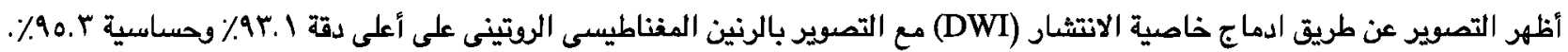
وقد خلصت نتائجنا إلى أن التصوير بالرنين المغناطيسى بخاصية الاتتشار (DWI) يزيد الثقة فى تقييم كتل المبيض. 